\title{
Tumorous neo-vascularization: a newly recognized endoscopic feature of intestinal non-Hodgkin lymphoma
}

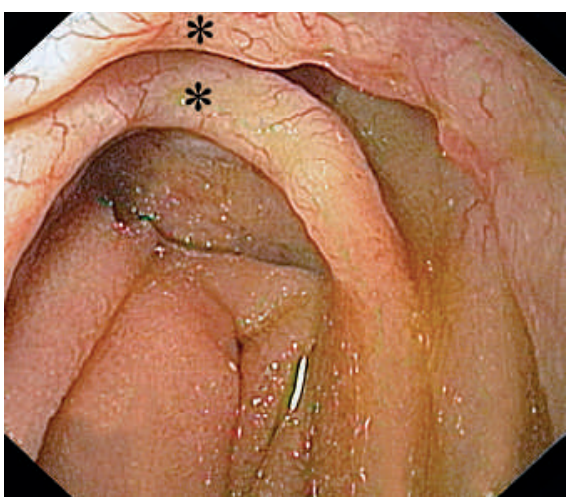

Figure 1 Push-enteroscopy. Extranodal marginal zone B-cell lymphoma of the proximal jejunum. Transverse folds are swollen, and no villi could be recognized. Multiple, tortuous, winding vessels are seen in affected folds (asterisks).

A 42-year-old man with Crohn's disease (since 1995) underwent control endoscopy in May 2005 (Figure 1). A diagnosis of extranodal marginal zone B-cell lymphoma of mucosa-associated lymphoid tissue (MALT)-type of the jejunum was made using histology and immunohistochemistry.

A 68-year-old man, who had previously undergone chemo- and radiotherapy for non-small-cell lung cancer (up to April 2005), was investigated in January 2006 following symptoms of diarrhea, abdominal colicky pain, frequent passage of mucus, and sporadic hematochezia (Figure 2 and 3). Diagnosis of diffuse large B-cell lymphoma of the colon was made using histology and immunohistochemistry.

Endoscopic features of intestinal lymphoma usually comprise infiltration of the intestinal wall: the affected segment is rigid, reddish, fragile, and often bleeds spontaneously. Irregular nodular pattern and multiple ulcers with scaring may also be found [ $1-3]$. We report two cases of macroscopically visible neo-vascularization as a newly recognized endoscopic feature of intestinal lymphoma. We consider these pathological, winding, tortuous vessels as a unique sign of tumorous angiogenesis. We can hypothesize that this could be stimulated by means of cytokines mediated by T-lymphocytes infil-

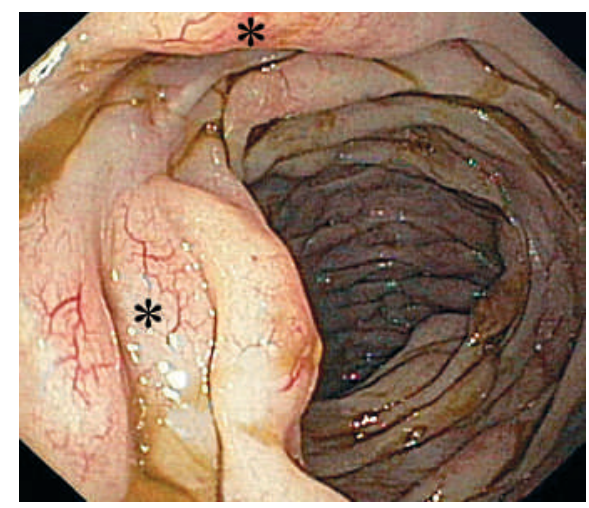

Figure 2 Colonoscopy. Diffuse large B-cell lymphoma of the ascending colon. Tumorous neo-vascularization is macroscopically apparent in the involved folds (asterisks).

trating margins of the neoplasm. Another possible factor is the bcl-2 family of proteins, which are considered to be responsible for pathological neo-vascularization in both human and experimental oncology $[4,5]$. In both our cases, B-lymphocytes also expressed bcl-2 proteins in the lymphoma.

In conclusion, awareness of this unusual, newly recognized endoscopic feature of winding, tortuous, tumorous vessels, in both small and large bowel lymphoma, may be helpful for timely diagnosis.

\section{Acknowledgement}

Supported in part by research project MZO 00179906 from the Ministry of Health of the Czech Republic.

Endoscopy_UCTN_Code_CCL_1AC_2AC

\section{Kopáčová', S. Rejchrt' ${ }^{1}$, V. Tyčová ${ }^{2}$,} D. Belada ${ }^{3}$, M. Pintérová Kolesárová1, J. Bureš 1

1 2nd Department of Internal Medicine, Charles University in Praha, Faculty of Medicine at Hradec Králové, University Teaching Hospital, Hradec Králové, Czech Republic

2 The Fingerland Department of Pathology, Charles University in Praha, Faculty of Medicine at Hradec Králové, University Teaching Hospital, Hradec Králové, Czech Republic
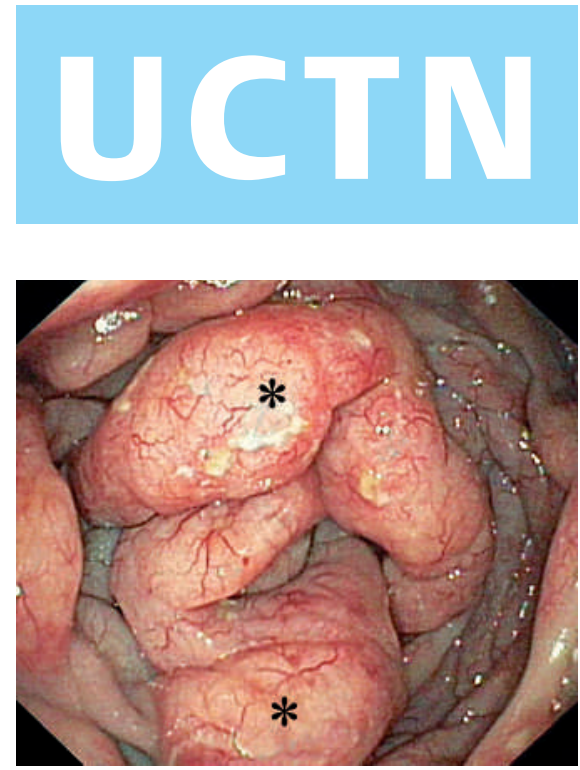

Figure 3 Colonoscopy. Diffuse large B-cell lymphoma of the rectum. Edematous and infiltrated folds (asterisks) create stenosis of the lumen. Multiple branching tumorous vessels are visible.

${ }^{3}$ Department of Clinical Haematology, Charles University in Praha, Faculty of Medicine at Hradec Králové, University Teaching Hospital, Hradec Králové, Czech Republic.

\section{References}

${ }^{1}$ Bureš J, Rejchrt S, Kopáčová M et al. Small Bowel Investigation and Atlas of Enteroscopy. Praha: Grada Publishing, 2001: 480

2 Myung SJ, Joo KR, Yang SK et al. Clinicopathologic features of ileocolonic malignant lymphoma: analysis according to colonoscopic classification. Gastrointest Endosc 2003; 57: $343-347$

${ }^{3}$ Yoshida N, Wakabayashi N, Nomura K et al. Ileal mucosa-associated lymphoid tissue lymphoma showing several ulcer scars detected using double-balloon endoscopy. Endoscopy 2004; 36: $1022-1024$

${ }^{4}$ Karl E, Warner K, Zeitlin B et al. Bcl-2 acts in a proangiogenic signaling pathway through nuclear factor-kappaB and CXC chemokines. Cancer Res 2005; 65: 5063-5069

${ }^{5}$ Trisciuoglio D, Iervolino A, Zupi G, Del Bufalo D. Involvement of PI3K and MAPK signaling in bcl-2-induced vascular endothelial growth factor expression in melanoma cells. Mol Biol Cell 2005; 16: 4153-4162

\section{Corresponding author}

\section{Kopáčová, MD}

2nd Department of Internal Medicine Charles University Teaching Hospital Sokolská 581 · 50005 Hradec Králové Czech Republic

Fax: $\quad+420-495-834785$

Email: kopacmar@fnhk.cz

DOI: 10.1055/s-2006-945163 